\title{
Airline Response to Changing Economics and Policy
}

\author{
John Ferguson (Ph.D. Candidate), Karla Hoffman (Ph.D.), Lance Sherry (Ph.D.), George Donohue \\ (Ph.D.), Abdul Qadar Kara (Ph.D. Candidate), Rosa Oseguera-Lohr (NASA, Ph.D.) \\ Center for Air Transportation Systems Research, George Mason University, Fairfax, VA
}

\begin{abstract}
Industry strategists, government regulators, and the media have focused on addressing concerns over the performance of the air transportation system with respect to delays. One of the strategies proposed has been to limit the scheduled operations at an airport to a-priori feasible capacity limits. This approach has been criticized on the basis that it would reduce the number of markets served and increase airfares.

This paper describes a comparison of the behavior of the air transportation system (e.g. markets served, airfares, delays, load factors, aircraft size) during the recent run-up in fuel prices at capacity-limited New York airports and non-slot controlled San Francisco and Philadelphia airports.

The results indicate:

i. Airfares change show a positive relationship to to changes in fuel prices

ii. Flights per day and Markets served show a positive relationship to changes in gross domestic product

iii. Flights per day and Markets served show a positive relationship to changes in airport capacity limits

iv. Delays and Cancellations change in proportion to Flights per day and Markets served
\end{abstract}

The implications of these results are discussed in this paper.

Keywords: Economic analysis, performance metrics, longitudinal analysis, airport delays, market analysis, metroplex.

\section{INTRODUCTION}

Nextgen plans to prepare the United States air transportation system for higher levels of air transportation demand than previously seen. NextGen will improve operations, by enabling aircraft to get into and out of the airport faster, while making better use of available airspace [1]. Thus Nextgen plans on using improved technology to handle greater air transportation demand and reduce the delays at the same time. However it is unlikely that increases in effective capacity will be sufficient to meet demand [2]. Researchers are applying more holistic approaches to the feedback control of the air transportation system [2]. Many of these approaches rely on an understanding of airline responses to changes in economics and policy, these responses include changes to their schedule, fleet and airfares.

Industry strategists, government regulators, and the media have focused on addressing concerns over the performance of the air transportation system with respect to delays. One of the strategies proposed has been to limit the scheduled operations at an airport to a-priori feasible capacity limits. This approach has been criticized on the basis that it would reduce the number of markets served and increase airfares.

Even modest changes in airline schedules in airports already operating at physical capacity can result in greater congestion throughout the air transportation network [3]. In 2007 and 2008, passengers flying domestic routes in the U.S. experienced nearly 300 million hours annually of passenger trip delays [4]. Previous studies have quantified a $\$ 41$ billion impact to the US Economy from passenger delay, but there has been less work that captures the direct costs to the airlines themselves and examines the behavior of the airlines when those costs change significantly [5] [6] [7].

Previous analysis has shown that airline behavior changes with changes in fuel prices [8]. This analysis examines the New York airports (Newark Liberty, New York John F. Kennedy, and LaGuardia), Philadelphia's airport (Philadelphia 
International), and the San Francisco airports (San Francisco International, San Jose, and Oakland) from January 2005 to December 2009 for trends in airline behavior and the impacts of this behavior on airport congestion and profitability. We refer to the collection of airports in a region as a "Metroplex". The two Metropolitan regions studied in this report are similar in that each has at least one airport that serves as a hub for a major carrier, has significant shuttle traffic as well as cross-continental and international traffic. The New York airports have capacity limits applied on their hourly operations while the San Francisco airports are not.

The New York airports are studied since they are responsible for $12 \%$ of total national delays it is the only region in the national network where all three major airports are slot controlled and this region has no ability to expand runway space at the existing airports [9]. During the summer of 2007 at LaGuardia, the average delay was over 70 minutes [10].

This study expands on prior efforts to analyze the behavior of airlines at congested airports [8]. It compares the performance at the New York airports to the performance at the Philadelphia and San Francisco airports from 2005 through 2009. During this time period, there were significant fluctuations in fuel prices and in the overall economic condition of the country. In addition, tighter regulations on the scheduling of flights at the three New York airports were imposed.

The results indicate that capacity limited airports yielded reduced congestion (e.g. less delayed and cancelled flights) through reductions in schedules and de-peaking schedules (see table 1). There was no significant change in markets serviced. While airfares were impacted by changes in fuel prices, they did not significantly increase at New York airports after capacity limits were applied.

San Francisco and Philadelphia airports reduced schedules as a result of bad economic conditions. These airports also reduced congestion through the reduction in schedules. Our overall conclusions are shown in Table 1.

\begin{tabular}{|l|c|c|c|c|c|c|c|}
\hline \multicolumn{4}{|c|}{ Annual Changes } & \multicolumn{4}{c|}{ Observations } \\
\hline & Caps & Economy & Fuel Prices & Airfare & Schedule & Congestion & Profit \\
\hline 05-06 & Yes & Up & Up & Up & No $\Delta$ & Up & Down \\
\hline 05-06 & No & Up & Up & Up & Up & Up & Down \\
\hline 06-07 & Yes & Up & No $\Delta$ & No $\Delta$ & No $\Delta$ & Up & Down \\
\hline 06-07 & No & Up & No $\Delta$ & No $\Delta$ & Up & Up & No $\Delta$ \\
\hline 07-08 & Yes & Constant & Up & Up & No $\Delta$ & No $\Delta$ & Down \\
\hline 07-08 & No & Constant & Up & Up & Down & Down & Down \\
\hline 08-09 & Reduced & Down & Down & Down & 2xDown & 2xDown & Up \\
\hline 08-09 & No & Down & Down & Down & Down & Down & Up \\
\hline
\end{tabular}

Table 1. Summary of Economic and Policy Changes on Airline Behavior and Airport Performance

The key observations from this analysis are as follows (table 1):

- Airfares change show a positive relationship to to changes in fuel prices

- Flights per day and Markets served show a positive relationship to changes in gross domestic product

- Flights per day and Markets served show a positive relationship to changes in airport capacity limits

- Delays and Cancellations change in proportion to Flights per day and Markets served

- Airline profitability shows a negative relationship to changes in airline airfares

- Airline profitability shows a negative relationship to changes in airport congestion

- Upgauging of airline fleets is unlikely to occur without the introduction of a new class of aircraft that has better efficiency for aircraft handling between 100-150 passengers.

- New York airports reacted differently to the new capacity limits, placed on these airports in 2008. LGA and EWR reduced schedules, because there was no opportunity to adjust their schedules to other timeslots. However JFK depeaked their schedule and maintained their flights per day volume.

- Reduced delays in 2008 did not provide airlines relief in delay costs because of the increased fuel costs.

- Airports with capacity limits reduced operations and congestion, while increasing profitability. 
- When the economy went into a severe recession, airports without capacity limits reduced operations and congestion, while increasing profitability.

The implications of these results are discussed.

Each of the New York Metroplex Airports restricts the use of runways by way of "slot" controls, referred to in this report as capacity limits. The Federal Government allocates a given number of slots in each 30-minute time period to the carriers that service the New York City area. A "slot" provides the holder with the right to announce either a departure or an arrival during this time period. Currently the San Francisco and Philadelphia airports do not have capacity limits in effect. Airlines at the three San Francisco airports can schedule flights well beyond the capacity of the runways. By doing comparisons of how the airlines in these two regions reacted, and also looking at an airport close to New York City, Philadelphia, we will examine how the airline industry responds to competition, changes in fuel costs, slot controls, and general economic condition. One reason for choosing to compare the New York City airports to the San Francisco airports is that the San Francisco Metroplex has been identified as a region needing additional capacity even after all planned improvements are made [11]. In addition, both the New York Metroplex and the San Francisco Metroplex exhibit significant shuttle and international traffic.

The organization of this paper is as follows: Section 2 describes the method of analysis. Section 3 describes the results of the analysis for airline, passenger and policy maker stakeholders. Section 4 discusses conclusions and future work.

\section{METHOD OF ANALYSIS}

This paper describes a longitudinal study, from 2005 through 2009, that evaluates airlines business and operational behaviors in response to economic and policy changes to the New York, Philadelphia and San Francisco airports. Figure 1 shows some triggers that may cause the airlines to change their behavior: tightened slot controls, changes in fuel prices, and economic changes, Based on these triggers, the airlines respond with changes to their schedules, prices, markets served and aircraft size.
The results of these actions by the airlines are the observed responses of the airspace system in terms of passenger responses to these prices, i.e. demand. The end result determines the profitability of the airlines and the overall use/congestion of the airspace.

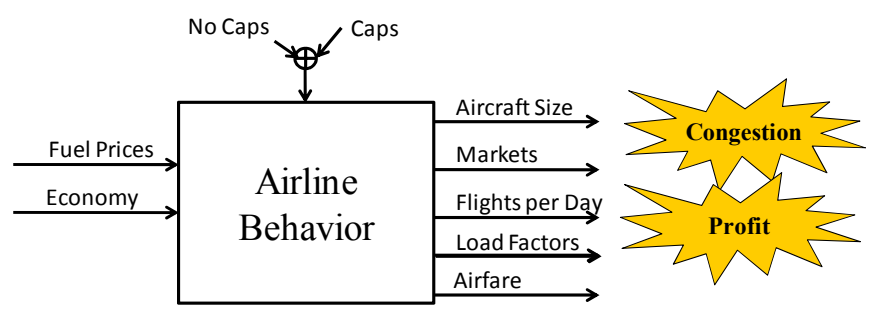

Figure 1. Objective of Analysis: How do Airlines respond to Economic and Policy Changes? How is Airport Congestion and Profitability Impacted by these responses?

Specifically this analysis examines airline schedule behavior by tracking (a) Aircraft size, (b) Flights per day, (c) Daily markets served and (d) average load factors. It also tracks airline (e) average ticket airfare on departures and arrivals. The impacts of these behaviors are examined by tracking (f) Airport congestion and (g) Profitability of the airports.

These metrics trends are measured summer to summer to capture the impacts from changes in fuel prices, economy (national gross domestic product) and capacity limits, see table 2 .

\begin{tabular}{|c|c|c|c|c|c|c|c|c|c|c|c|c|}
\hline & \multicolumn{3}{|c|}{$2005-2006$} & \multicolumn{3}{|c|}{$2006-2007$} & \multicolumn{3}{|c|}{ 2007-2008 } & \multicolumn{3}{|c|}{ 2008-2009 } \\
\hline Regions & NY & PHL & SF & NY & PHL & SF & NY & PHL & SF & NY & PHL & SF \\
\hline $\begin{array}{l}\text { Fuel } \\
\text { Prices }\end{array}$ & \multicolumn{3}{|c|}{$+21 \%$} & \multicolumn{3}{|c|}{ No Change } & \multicolumn{3}{|c|}{$+72 \%$} & \multicolumn{3}{|c|}{$-47 \%$} \\
\hline Economy & \multicolumn{3}{|c|}{$+2.7 \%$} & \multicolumn{3}{|c|}{$+2.1 \%$} & \multicolumn{3}{|c|}{$+0.4 \%$} & \multicolumn{3}{|c|}{$-2.4 \%$} \\
\hline $\begin{array}{l}\text { Capacity } \\
\text { Limits }\end{array}$ & \multicolumn{3}{|c|}{ No Change } & \multicolumn{3}{|c|}{ No Change } & \multicolumn{3}{|c|}{ No Change } & \multicolumn{3}{|c|}{$\begin{array}{c}\text { Effect of } 2008 \\
\text { caps at EWR, } \\
\text { JFK and LGA } \\
\text { seen here }\end{array}$} \\
\hline
\end{tabular}

Table 2. Remarkably transient period for economy, regulation and fuel price changes

First, we evaluated these metrics by comparing how each airport responded to these changes across the five years of the study. Next, we preformed the same analysis but treating a region as a single entity (i.e. we combined the three New York airports and similarly the three San Francisco airports into 
Metroplex statistics). Finally, we compared the responses of the airlines across all seven airports to see if there were regional differences or specific airport differences in the responses.

\section{Study Questions}

This complex multi-stakeholder analysis of the New York, Philadelphia and San Francisco Airports is designed to answer the following questions:

- How have NY, SF and PHL airports responded to policy and economic changes from 2005 to 2009 ?

1. Increases/ Decreases in Fuel Prices?

2. Increases/Decreases in Economic Changes? We will measure these changes by using Gross Domestic Product (GDP) as a measure of economic growth/recession.

3. Capacity Limits?

- Have capacity limits affected each of the NY airports the same way?

- Did capacity limits at the NY Airports reduce Delays? Reduce delay costs?

- Where any airports more resilient to these changes than others?

\section{Airline Behavior Metrics}

Below we define the following metrics that were used in our analysis to measure airline behavior in response to economic and policy changes.

Aircraft size: The average number of seats per aircraft for various $\mathrm{O} / \mathrm{D}$ pairs as reported to BTS [12].

Flights per day: The number of arrivals per day from other Metroplexes as reported to the Bureau of Transportation Statistics (BTS) [12]. Markets Served: A count of the number of destinations served from a NY/NJ airport with at least sixty or more arrivals and departures per month, as reported to BTS [12].

Load Factor: The number of passengers on a given aircraft divided by the seat capacity of that aircraft, as reported to BTS [12].

Average Airfare: We report the average airfare during a given quarter, as reported in the $10 \%$ price sample provided to BTS [12]. This analysis does not completely include the passenger's cost of travel since it does not reflect any baggage, fuel fees, or other incidentals (e.g. blanket, movie, food).

\section{Performance Impact Metrics}

We record the response to these airline actions using the following metrics:

Flight Delay: We report the number of delayed flights (flights with delays of 15 minutes or more), as reported to BTS [12].

Flight Cancellations: Flight cancellations count the total number of flights cancelled for each $\mathrm{O} / \mathrm{D}$, as reported to BTS [12].

Congestion: Percentage change in the number of flights delayed above 15 minutes plus percentage change in the number of flights cancelled divided by two. Thus, we are averaging the two measures related to delay. Airline Revenue: For each market, the revenue is determined by calculating the average single segment fare for that $\mathrm{O} / \mathrm{D}$ pair and multiplying this average fare by the total passengers flown in that quarter. Thus, revenue does not include any additional fees charged by the airline, Airline Costs: Costs include personnel, fuel, insurance, taxes, maintenance, and depreciation per flight hour and reported to BTS by aircraft type. Airline costs do no include any additional costs that the airline might incur due to delays in schedules. Airline costs as reported here is calculated by multiplying average flight times (in minutes) as reported in the Aviation system performance metrics (ASPM) by aircraft cost per flight minute and then multiplying the result by the number of flights per quarter [13].

Profitability: Percentage change in airline revenue minus percentage change in airline operations cost as reported in BTS [12].

Delay Costs: In addition, we estimate the operational cost of delay by using a model derived from the EuroControl 2004 study of airline delays [14]. For more on these calculations see the paper on a domestic delay cost model by Kara, et.al. [15]. The model is additive with four components to the overall cost: fuel costs, crew costs, maintenance costs and all other costs. The costs are segmented into short, medium and long delays. 


\section{RESULTS OF ANALYSIS}

\section{SUMMARY OF ANALYSIS}

The analysis showed a positive relationship between airfare and fuel prices, Gross Domestic Product and airline schedule, capacity limits and airline schedule, and between airline schedule and airport congestion. A negative relationship was found between airfare and airport profitability and between airport congestion and airport profitability.

The analysis showed no significant change in load factors, or aircraft size. The upgauging of aircraft is unlikely to occur without the introduction of a new class of aircraft that has better efficiency for aircraft handling between 100-150 passengers.

The following sections explain these findings in greater detail.

\section{AIRLINE SCHEDULE OBSERVATIONS}

The capacity limits applied at New York airports affected the New York airports differently. While airlines operating out of LGA and EWR reduced their schedules the airlines operating out of JFK depeaked their schedule. This was mostly due to the fact that LGA and EWR were already operating at capacity, while JFK had plenty of capacity still available during non-peak periods, see figures 2-4.

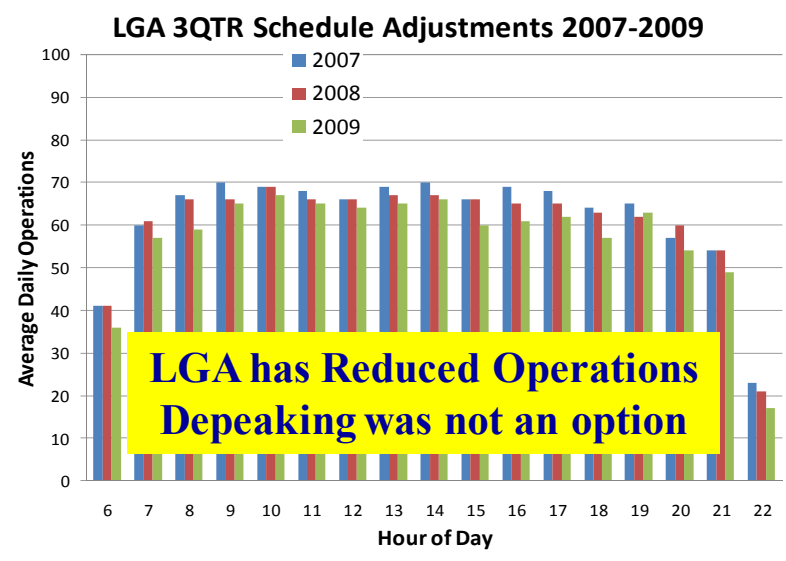

Figure 2. LGA Reduces Operations

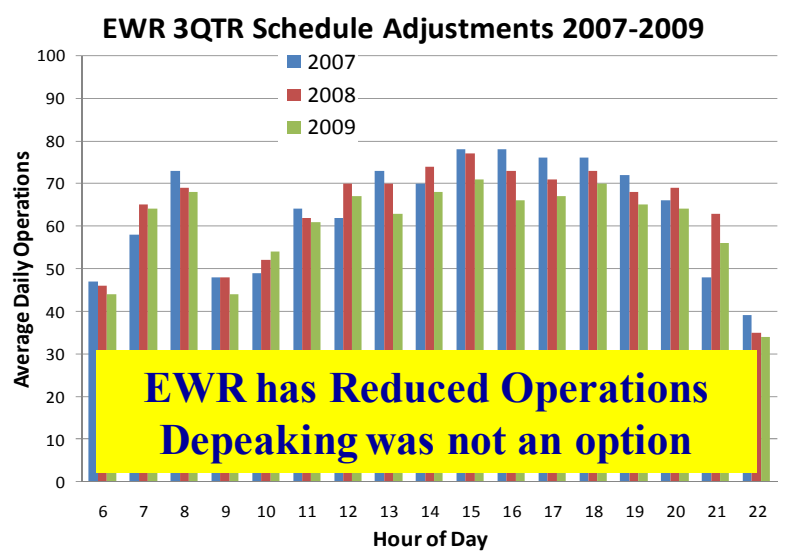

Figure 3. EWR Reduces Operations

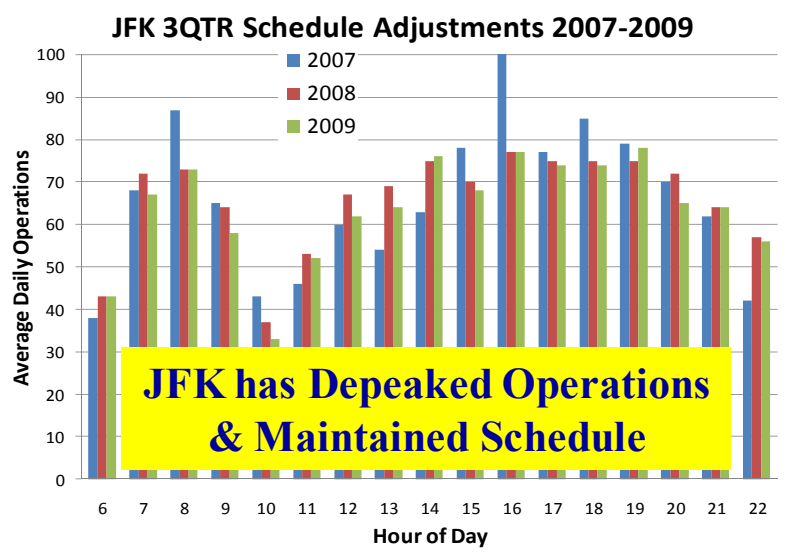

Figure 4. JFK Depeaks Operations

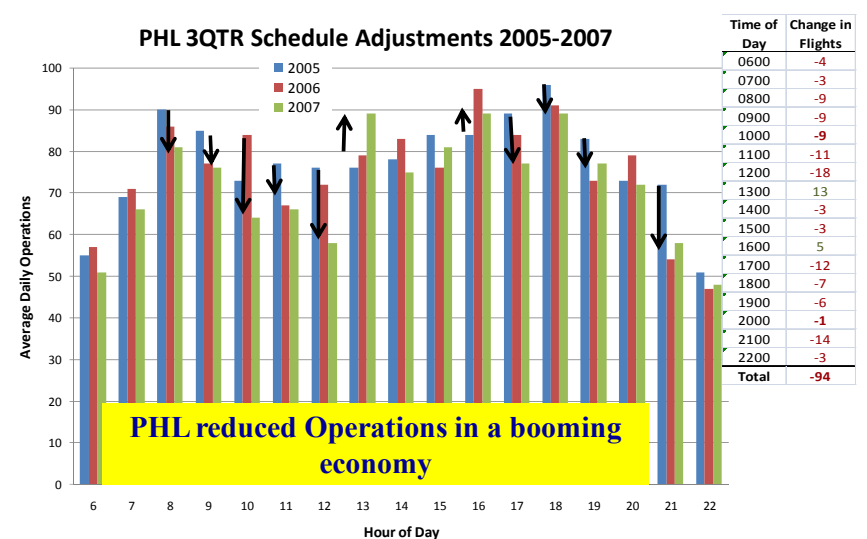

Figure 5. PHL Reduces Operations (2005-2007)

While the economy was booming from 2005 to 2007 airline schedules at PHL were reduced, as shown in figure 5 . This reduction could be explained by the consolidation of schedules after the merger of US Airways and America West Airlines in 2005. 


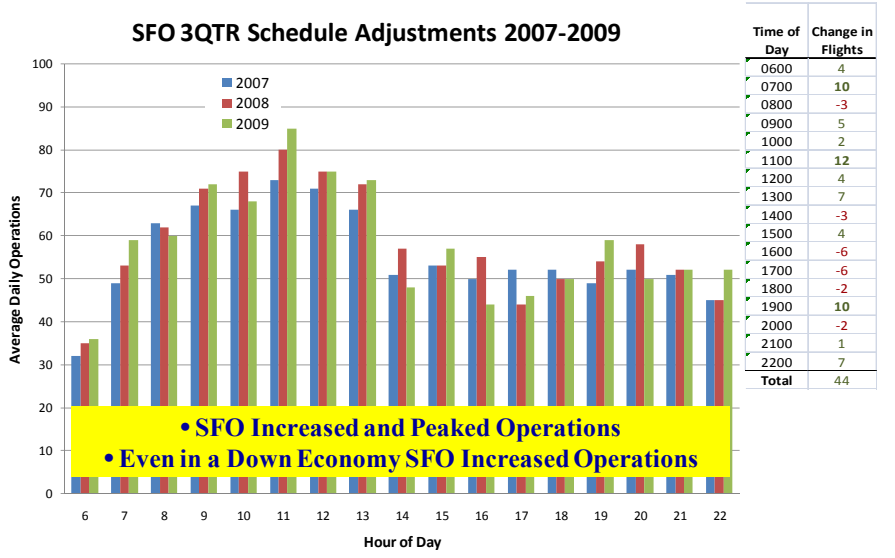

While the economy was in recession from 2007 to 2009 SFO airlines increased schedules as shown in figure 6.

Figure 6. SFO Increases Operations (2007-2009)

\begin{tabular}{|c|c|c|c|c|c|c|c|c|}
\hline \multicolumn{2}{|c|}{ Historical Changes } & & \multicolumn{6}{|c|}{ Longitudinal Metrics } \\
\hline Fuel Prices & Economy & Airport & A/C Size & Markets & Flights/ Day & Airfare & Congestion & Profit \\
\hline \multirow{5}{*}{$\begin{array}{c}21 \% 2005- \\
2006\end{array}$} & \multirow{5}{*}{$2.7 \%$} & LGA & no change & $-3 \%$ & no change & $10 \%$ & $5 \%$ & $-5 \%$ \\
\hline & & EWR & $3 \%$ & no change & no change & no change & $11 \%$ & no change \\
\hline & & JFK & no change & no change & $4 \%$ & $12 \%$ & $-3 \%$ & $-9 \%$ \\
\hline & & PHL & $-4 \%$ & $-10 \%$ & $-16 \%$ & $13 \%$ & $-34 \%$ & $5 \%$ \\
\hline & & $\mathrm{SFO}$ & no change & $8 \%$ & $3 \%$ & $7 \%$ & $40 \%$ & no change \\
\hline \multirow{5}{*}{$\begin{array}{c}1 \% 2006- \\
2007\end{array}$} & \multirow{5}{*}{$2.1 \%$} & LGA & no change & no change & $-3 \%$ & no change & $21 \%$ & $-13 \%$ \\
\hline & & EWR & no change & no change & no change & no change & $23 \%$ & $-12 \%$ \\
\hline & & JFK & $-12 \%$ & $8 \%$ & $20 \%$ & $4 \%$ & $111 \%$ & $4 \%$ \\
\hline & & PHL & no change & no change & $-4 \%$ & no change & $32 \%$ & no change \\
\hline & & SFO & no change & no change & $4 \%$ & no change & $6 \%$ & no change \\
\hline \multirow{5}{*}{$\begin{array}{c}72 \% 2007- \\
2008\end{array}$} & \multirow{5}{*}{$0.4 \%$} & LGA & no change & $-4 \%$ & no change & $11 \%$ & no change & $-17 \%$ \\
\hline & & EWR & no change & $4 \%$ & $-8 \%$ & $11 \%$ & $-13 \%$ & $-32 \%$ \\
\hline & & JFK & $3 \%$ & no change & $-5 \%$ & $8 \%$ & $-22 \%$ & $-22 \%$ \\
\hline & & PHL & no change & no change & $-4 \%$ & $11 \%$ & $-25 \%$ & $-18 \%$ \\
\hline & & SFO & no change & no change & $4 \%$ & no change & $20 \%$ & $-20 \%$ \\
\hline \multirow{5}{*}{$\begin{array}{c}-47 \% \text { o 2008- } \\
2009 \text { (*caps in } \\
\text { NY) }\end{array}$} & \multirow{5}{*}{$-2.4 \%$} & LGA* & no change & \begin{tabular}{|l|}
$-10 \%$ \\
\end{tabular} & $-16 \%$ & $-13 \%$ & $-30 \%$ & $9 \%$ \\
\hline & & EWR* & no change & $-12 \%$ & $-16 \%$ & $-10 \%$ & $-31 \%$ & $10 \%$ \\
\hline & & JFK* & no change & no change & no change & $-13 \%$ & $-16 \%$ & $11 \%$ \\
\hline & & PHL & no change & \begin{tabular}{|l|}
$-6 \%$ \\
\end{tabular} & $-7 \%$ & $-10 \%$ & $-20 \%$ & $9 \%$ \\
\hline & & SFO & no change & $-8 \%$ & $-4 \%$ & $-9 \%$ & $-29 \%$ & $25 \%$ \\
\hline
\end{tabular}

Table 3. Annual Economic and Policy Changes, Airline Behavior and Airport Performance (2005-2009)

\section{AIRLINE ANNUAL TRENDS}

Table 3 highlights the summer to summer airline behavior, congestion and profit trends for the five major airports in New York, Philadelphia, and San Francisco. When fuel price growth is modest, increased congestion leads to reduced profitability. Under similar modest fuel price growth reduced congestion leads to increased profitability.

\section{Load Factors and Aircraft Size (Gauge)}

This analysis showed no change in airline load factors and little change in aircraft size. Many had hoped that when congestion increased substantially or when slot controls were imposed the airline would respond by upgauging the airplanes used on these routes. We did not observe this behavior. When examining the data more closely, we see that there are economies of scale related to crew and maintenance costs. However, there are no such economies of scale related to fuel costs. The newest part of the airline industry fleet is regional jets that are more fuel efficient that the larger aircraft in the overall fleet. Thus, as fuel prices increase, there is more incentive for the airlines to move to smaller aircraft. Figure 7 illustrates this point where we see that the smaller aircraft have better average fuel usage per seat hour. The A787 
and A380 are more efficient aircraft but unlikely to be used for many of the markets currently served by these airports since they are relatively large aircraft.

By using smaller aircraft the airlines can assure high load factors, greater frequency. This result has significant implications for future airspace use.

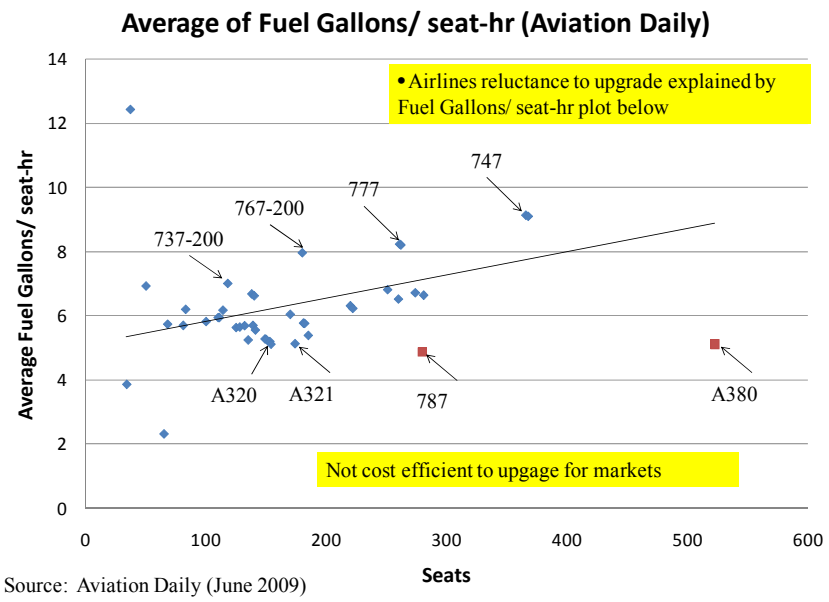

Figure 7. Aircraft Burn Rate/Seat-Hr versus Seat Size (Not Efficient for Airlines to Upgauge)

\section{Airfare}

Increases in fuel prices leads to increased airfares and decreases fuel prices leads to decreased airfares. Gross Domestic Product and capacity limits seem to have no effect on airfare, as shown in table 4.

\begin{tabular}{|l|c|c|c|c|c|c|c|}
\hline \multicolumn{4}{|c|}{ Annual Changes } & \multicolumn{5}{c|}{ Observations } \\
\hline & Caps & Economy & Fuel Prices & Airfare & Schedule & Congestion & Profit \\
\hline $05-06$ & Yes & Up & Up & Up & No $\Delta$ & Up & Down \\
\hline $05-06$ & No & Up & Up & Up & Up & Up & Down \\
\hline $06-07$ & Yes & Up & No $\Delta$ & No $\Delta$ & No $\Delta$ & Up & Down \\
\hline 06-07 & No & Up & No $\Delta$ & No $\Delta$ & Up & Up & No $\Delta$ \\
\hline 07-08 & Yes & Constant & Up & Up & No $\Delta$ & No $\Delta$ & Down \\
\hline 07-08 & No & Constant & Up & Up & Down & Down & Down \\
\hline 08-09 & Reduced & Down & Down & Down & 2xDown & 2xDown & Up \\
\hline $08-09$ & No & Down & Down & Down & Down & Down & Up \\
\hline
\end{tabular}

Airfare appears to only be effected by Fuel Price changes

- Increased/Decreased fuel prices lead to increased/decreased airfares

Table 4. Fuel Price Effects on Airfare (20052009)

Figure 8 shows how airfare has changed over time for the New York, Philadelphia and San Francisco airports. Until the end of 2006, JFK was trending with LGA and PHL. Thereafter, JFK seems to be performing more like EWR and SFO.

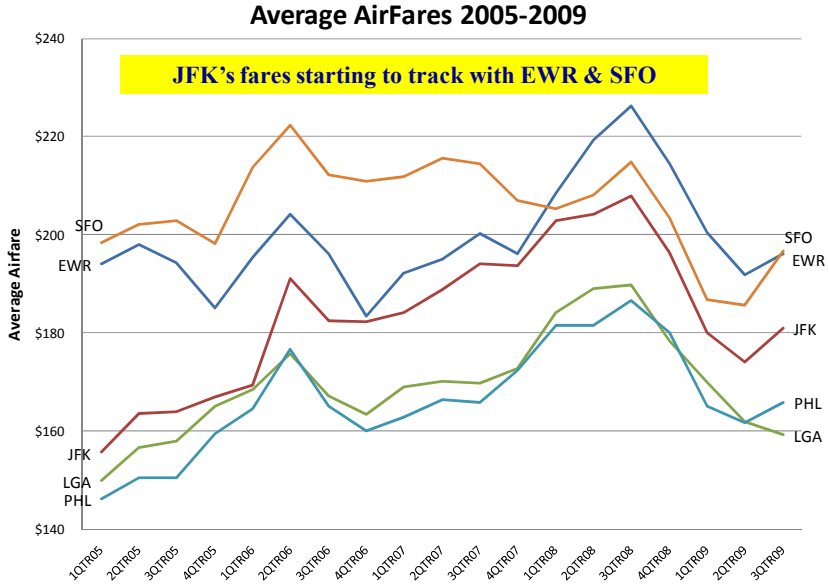

Figure 8. Average Airfares (2005 to 2009)

\section{Airline Schedule}

Airline schedule behavior can be observed by examining the trends in aircraft size, markets served and flights per day. The average size of aircraft used did not change throughout this study with the exception of JFK. Delta Airlines entered JFK as a hub for international travel. They used smaller aircraft to get passengers to this hub and the size of aircraft therefore was reduced directly after the entry of Delta to this airport.

Markets served and flights per day were found to track well with changes in the national economy and the introduction of new or reduced capacity limits, as shown in table 5. During good economic times, the number of markets served and flights per day increased and during bad times they were reduced. In terms of slot controls, as these controls were imposed or tightened, the number of markets served or flights per days decreased.

Most surprisingly, airline schedules seemed insensitive to changes in fuel prices. In table 5, the metrics for markets served and flights per day are combined into the metric labeled schedule, since both metrics followed similar trends.

All airports observed reduced their schedule from 2008 to 2009 as the result of the recession. The New York airports with new or reduced capacity limits reduced their schedules twice as much as did SFO as shown in table 5. Fuel prices did not affect schedules at these congested airports. 
All airports reduced schedule during economic downturn.

-Twice the reductions occurred where caps were applied/reduced (LGA, EWR)

Economic growth leads to schedule growth where possible -No growth observed at capped or capacitated airports (LGA, EWR)

Fuel prices do not appear to effect schedules at congested airports

\begin{tabular}{|c|c|c|c|c|c|c|c|}
\hline & \multicolumn{3}{|c|}{ Annual Changes } & \multicolumn{4}{c|}{ Observations } \\
\hline & Caps & Economy & Fuel Prices & Airfare & Schedule & Congestion & Profit \\
\hline $05-06$ & No & Up & Up & Up & Up & Up & Down \\
\hline $06-07$ & No & Up & Constant & No $\Delta$ & Up & Up & No $\Delta$ \\
\hline $05-06$ & Yes & Up & Up & Up & No $\Delta$ & Up & Down \\
\hline $06-07$ & Yes & Up & Constant & No $\Delta$ & No $\Delta$ & Up & Down \\
\hline $07-08$ & Yes & Constant & Up & Up & No $\Delta$ & No $\Delta$ & Down \\
\hline $07-08$ & No & Constant & Up & Up & Down & Down & Down \\
\hline $08-09$ & No & Down & Down & Down & Down & Down & Up \\
\hline $08-09$ & Reduced & Down & Down & Down & 2xDown & 2xDown & Up \\
\hline
\end{tabular}

Table 5. Economic and Policy Effects on Schedule (2005-2009)

\section{Flights per day}

Increases in national Gross Domestic Product at SFO an unconstrained airport leads to increased flights per day. And decreases in national Gross Domestic Product leads to decreased flights per day. Fuel prices seem to have no effect on flights per day.

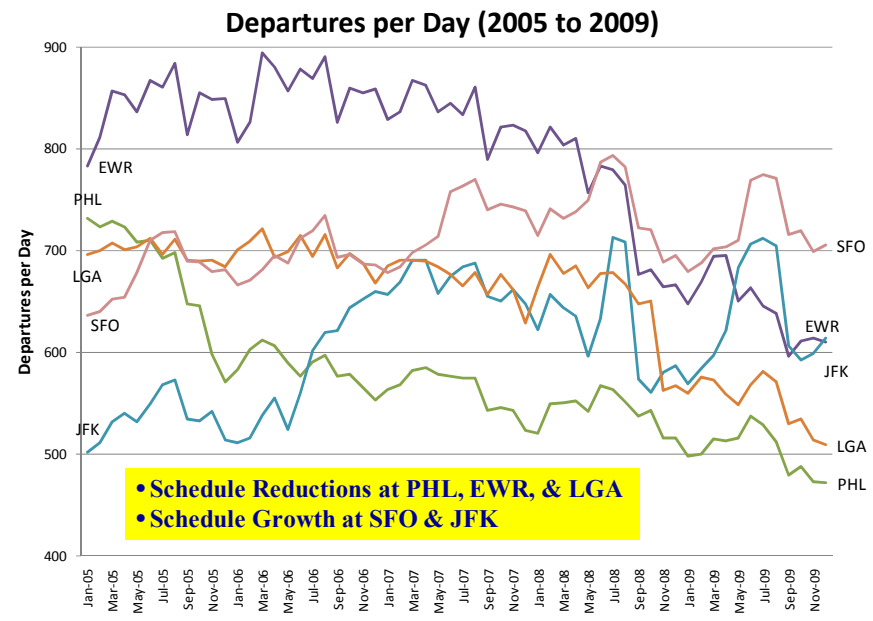

Figure 9. Departures per Day (2005 to 2009)

As mentioned and illustrated earlier, the capacity limits introduced in 2008 in New York, caused LGA and EWR to reduce schedules and JFK to depeak schedules.

Figure 9 illustrates the reduction in operations over time for PHL, EWR and LGA. During the same time period, SFO and JFK operations have grown.

\section{Markets}

As was the case with flights per day, increases in national Gross Domestic Product at SFO (an unconstrained airport) leads to increased markets. Similarly, the recession led to decreased markets. Fuel prices seem to have no effect on markets.

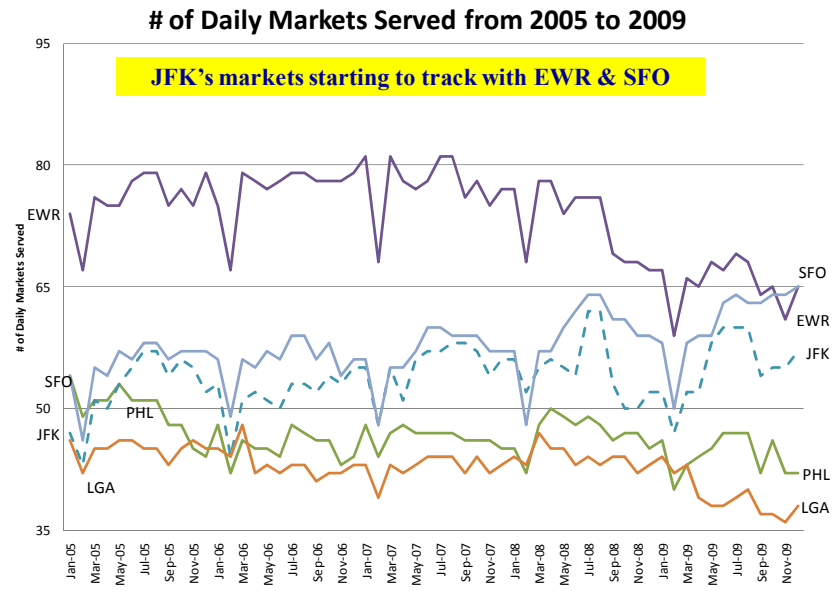

Figure 10. Daily Markets Served (2005 to 2009)

The capacity limits (slot controls) introduced in 2008 in New York; seem to have caused LGA and EWR to reduce markets where as JFK had the opportunity to depeak rather than reduce the markets served.

Figure 10 illustrates the reduction in markets over time for PHL, EWR and LGA, while SFO and JFK markets have grown.

\section{Congestion}

This analysis is confounded by airport growth at JFK with the introduction of significant Delta Airline Operations by the summer of 2007. The Southwest Airlines purchase of ATA lead to consolidation of services in SFO from SJC and OAK in 2008. Additionally PHL consolidated operations in 2006. Therefore these airports will not always track with the observed trends from economic and policy changes. 


Growth in Airline Schedules lead to Increased Congestion
Reduced Airline Schedules lead to Reduced Congestion
\begin{tabular}{|c|c|c|c|c|c|c|c|}
\hline \multicolumn{2}{|c|}{ Annual Changes } & \multicolumn{5}{c|}{ Observations } \\
\hline & Caps & Economy & Fuel Prices & Airfare & Schedule & Congestion & Profit \\
\hline $05-06$ & Yes & Up & Up & Up & No $\Delta$ & Up & Down \\
\hline $05-06$ & No & Up & Up & Up & Up & Up & Down \\
\hline $06-07$ & Yes & Up & Constant & No $\Delta$ & No $\Delta$ & Up & Down \\
\hline $06-07$ & No & Up & Constant & No $\Delta$ & Up & Up & No $\Delta$ \\
\hline $07-08$ & Yes & Constant & Up & Up & No $\Delta$ & No $\Delta$ & Down \\
\hline $07-08$ & No & Constant & Up & Up & Down & Down & Down \\
\hline $08-09$ & Reduced & Down & Down & Down & 2xDown & 2xDown & Up \\
\hline $08-09$ & No & Down & Down & Down & Down & Down & Up \\
\hline
\end{tabular}

Table 6. Airline Schedule Effects on Congestion (2005-2009)

Table 6 illustrates the impact of airline schedules on airport congestion. As expected growth in airline schedules leads to increased congestion (delays and cancellations) and reductions in schedule reduce airport congestion.

The capacity limits applied at New York airports seems to have reduced congestion for EWR and LGA, since reductions in congestion are 50\% higher than that observed at JFK and PHL.

Additional analysis of the schedules shown in figures 2-4 illustrates that EWR and LGA reduced their schedules and JFK depeaked its schedule.

\section{Profitability}

The analysis shows a negative relationship between airline airfares and airport profitability as shown in table 7. When airfares are increased airport profitability is reduced and when airfares are reduced airport profitability is increased. We also observed fuel prices increased more than airfares. Also note that extra bag fees and other new fees introduced by the airlines are not included in this analysis so the conclusions may be be misleading since these fees now account for a considerable addition to the airline revenue.

Increased/Decreased airfares lead to reduced/increased profitability*
Increased/Reduced congestion leads to reduced/increased profitability
\begin{tabular}{|c|c|c|c|c|c||c|c||}
\hline & \multicolumn{3}{|c|}{ Annual Changes } & \multicolumn{5}{|c|}{ Observations } \\
\hline & Caps & Economy & Fuel Prices & Airfare & Schedule & Congestion & Profit \\
\hline $05-06$ & Yes & Up & Up & Up & No $\Delta$ & Up & Down \\
\hline $05-06$ & No & Up & Up & Up & Up & Up & Down \\
\hline $06-07$ & Yes & Up & Constant & No $\Delta$ & No $\Delta$ & Up & Down \\
\hline $06-07$ & No & Up & Constant & No $\Delta$ & Up & Up & No $\Delta$ \\
\hline $07-08$ & Yes & Constant & Up & Up & No $\Delta$ & No $\Delta$ & Down \\
\hline $07-08$ & No & Constant & Up & Up & Down & Down & Down \\
\hline $08-09$ & Reduced & Down & Down & Down & $2 \times D o w n$ & $\mathbf{2 x D o w n ~}$ & Up \\
\hline $08-09$ & No & Down & Down & Down & Down & Down & Up \\
\hline
\end{tabular}

${ }^{*}$ Fuel prices increase more than airfares

*Baggage and other airline fees not included in profitability calculation

Table 7. Airline Airfare and Airport Congestion Effects on Profitability (2005-2009)

The analysis also shows a negative relationship between airport congestion and airport profitability as shown in table 7 . When airport congestion is increased profitability is reduced and when airport congestion is reduced airport profitability is increased.

When analyzing the airline delay costs from 2005 to 2009 , figure 11 shows that even though delays were down in 2008 versus 2007, delay costs still increased. This was primarily due to the sharp increases in fuel prices in 2008.

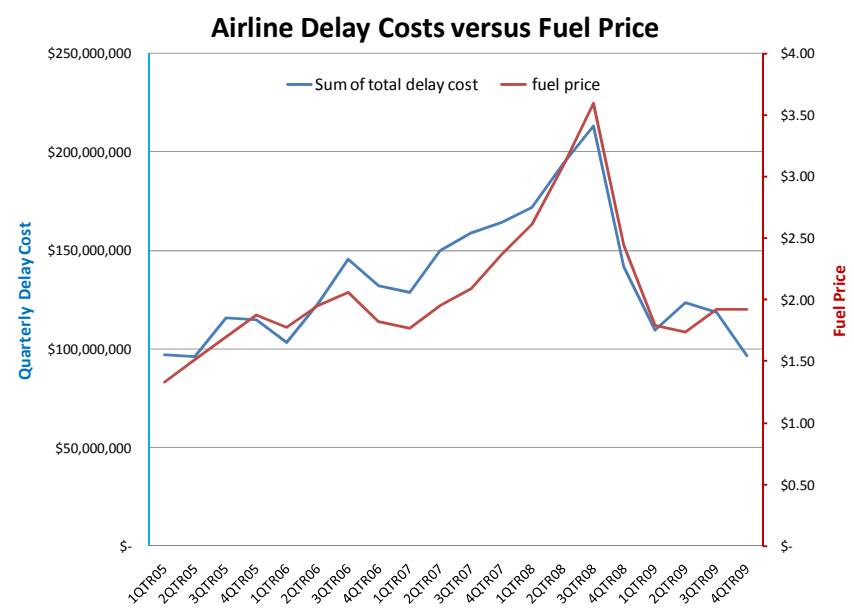

Figure 11. Delay Cost versus Fuel Price

\section{REGIONAL ANNUAL TRENDS}

Table 8 highlights the annual trends for regional aircraft size, markets served, flights per day, airfare, congestion and profitability trends for the New York, Philadelphia, and San Francisco 
regional areas. Again trends are confounded by events at JFK, SFO and PHL.

Although we observe trends similar to those at the individual airports, the amount of the increases/decreases are dampened by the interaction of airports within the regions.

The regional (metroplex) analysis highlighted in table 8 shows the annual impact of economic and policy changes to these airport regions. This analysis combined with the individual airport analysis shows the inter-regional interaction of airports in response to economic and policy changes.

This analysis shows how JFK and SFO additional capacity have allowed them to increase operations and reduce the overall economic and policy impact to these regions. This analysis shows again that adding capacity limits to New York airports did not cause significant loss of markets, operations or significant increases in airfares in the region. The capacity limits combined with the economic recession have significantly reduced congestion in New York, to levels below 2005 congestion.

\begin{tabular}{|c|c|c|c|c|c|c|c|c|}
\hline \multicolumn{2}{|c|}{ Historical Changes } & \multirow[b]{2}{*}{ Region } & \multicolumn{6}{|c|}{ Longitudinal Metrics } \\
\hline Fuel Prices & Economy & & \begin{tabular}{l|l|} 
A/C Size & \\
\end{tabular} & Markets & Flights/Day & \begin{tabular}{|l|} 
Airfare \\
\end{tabular} & Congestion & Profit \\
\hline \multirow{3}{*}{$\begin{array}{c}21 \% \text { 2005- } \\
2006\end{array}$} & \multirow{3}{*}{$2.7 \%$} & NY & no change & no change & no change & $8 \%$ & $6 \%$ & $-5 \%$ \\
\hline & & PHL & \begin{tabular}{|l|}
$-4 \%$ \\
\end{tabular} & $-10 \%$ & $-16 \%$ & $13 \%$ & $-34 \%$ & $5 \%$ \\
\hline & & SF & $3 \%$ & no change & $3 \%$ & $13 \%$ & $27 \%$ & $0 \%$ \\
\hline \multirow{3}{*}{$\begin{array}{c}1 \% 2006- \\
2007\end{array}$} & \multirow{3}{*}{$2.1 \%$} & $\mathrm{NY}$ & $-3 \%$ & no change & $3 \%$ & no change & $37 \%$ & $-5 \%$ \\
\hline & & PHL & no change & no change & $-4 \%$ & no change & $32 \%$ & $0 \%$ \\
\hline & & SF & no change & no change & no change & no change & $3 \%$ & $-4 \%$ \\
\hline \multirow{3}{*}{$\begin{array}{c}72 \% \text { 2007- } \\
2008\end{array}$} & \multirow{3}{*}{$0.4 \%$} & $\mathrm{NY}$ & no change & no change & $-5 \%$ & $10 \%$ & $-11 \%$ & $-26 \%$ \\
\hline & & PHL & no change & no change & $-4 \%$ & $11 \%$ & $-25 \%$ & $-18 \%$ \\
\hline & & SF & no change & no change & $-3 \%$ & $3 \%$ & $9 \%$ & $-26 \%$ \\
\hline \multirow{3}{*}{$\begin{array}{c}-47 \% \text { 2008- } \\
2009 \text { (caps in } \\
\text { NY) }\end{array}$} & \multirow{3}{*}{$-2.4 \%$} & $\mathrm{NY}$ & no change & $-7 \%$ & $-11 \%$ & $-12 \%$ & $-27 \%$ & $10 \%$ \\
\hline & & PHL & no change & no change & $-7 \%$ & $-10 \%$ & $-20 \%$ & $9 \%$ \\
\hline & & SF & \begin{tabular}{|c|}
$-6 \%$ \\
\end{tabular} & \begin{tabular}{|c|}
$-6 \%$ \\
\end{tabular} & $-11 \%$ & $-6 \%$ & $-31 \%$ & $20 \%$ \\
\hline
\end{tabular}

Table 8. Regional Annual Trends

\section{4-YEAR AIRPORT TRENDS}

Table 9 highlights four year trend observed for the airports examined in this study. We observe significantly different behavior as a response to the economic and policy changes depending on whether the airport is expanding, contracting or is at capacity.

The 4-year trends highlighted in table 9 shows the overall effect of economic and policy changes or shocks to the airports. This analysis shows that SFO and JFK have been more resilient to the economic and policy changes over the past 4 years than the other airports examined.

\begin{tabular}{|c|c|c|c|c|c|c|c|}
\hline \multirow{4}{*}{$\begin{array}{l}\text { Airports } \\
\text { Expanding }\end{array}$} & & \multicolumn{6}{|c|}{2005 to 2009 Trends } \\
\hline & & A/C Size & Markets & Flights/Day & Airfare & Congestion & Profit \\
\hline & SFO & none & none & $7 \%$ & $-6 \%$ & $22 \%$ & $18 \%$ \\
\hline & JFK & $-12 \%$ & $6 \%$ & $20 \%$ & $11 \%$ & $30 \%$ & $-10 \%$ \\
\hline \multirow{3}{*}{$\begin{array}{c}\text { Airports at } \\
\text { Capacity }\end{array}$} & EWR & $2 \%$ & $-13 \%$ & $-22 \%$ & none & $-17 \%$ & $-24 \%$ \\
\hline & LGA & $-2 \%$ & $-11 \%$ & $-20 \%$ & $6 \%$ & $-13 \%$ & $-12 \%$ \\
\hline & PHL & $-6 \%$ & $-13 \%$ & $-28 \%$ & $10 \%$ & $-49 \%$ & none \\
\hline \multirow{2}{*}{$\begin{array}{l}\text { Airports } \\
\text { Contracting }\end{array}$} & SJC & $2 \%$ & -13 & -16 & $5 \%$ & $-24 \%$ & $6 \%$ \\
\hline & OAK & none & $9 \%$ & $-28 \%$ & $3 \%$ & $-27 \%$ & none \\
\hline
\end{tabular}

Significant Different Behavior Observed by Airports experiencing different business trends

Table 8. Airport 4-Year Trends

This analysis also illustrates that the policy impacts have had minimal impact on number of markets served or on airfares.During the imposition of these capacity controls, JFK has thrived because it had the opportunity to depeak its schedule. The capacity limits combined with the economic recession have significantly reduced congestion in New York, to levels below 2005 congestion.

\section{CONCLUSIONS and FUTURE WORK}

\section{Conclusions}

Analysis of the New York, San Francisco, and Philadelphia airports from 2005 to 2009 showed that Increases/ Decreases in Fuel Prices resulted in corresponding increases/ decreases in airfares and decreases/ increases in airline profitability. Increases in Gross Domestic Product resulted in corresponding increases in airport operations and markets. Decreases in Gross Domestic Product resulted in corresponding decreases in airport operations and markets.

Analysis of the New York airports from 2005 to 2009 showed that capacity limits resulted in reduced operations at capacitated (EWR \& LGA) airports and depeaking of operations at JFK. Reduced airline operations as the result of capacity limits led to reduced airport congestion and increased airline profitability at these airports. Additional analysis showed that even though delays were down in 2008 versus 2007, delay costs 
increased primarily due to the sharp increases in fuel prices in 2008.

New York John F. Kennedy (JFK) and San Francisco International (SFO) airports were found to be more resilient to the economic and policy changes over the past 4 years than the other airports examined. In both airports, operations and revenues have increased during the past 4 years of economic turmoil.

The results indicate that capacity limited airports yielded improved performance (e.g. flight delays and cancelled flights) through reductions in frequency and de-peaking schedules. The airports in the San Francisco and Philadelphia region showed the same behavior as if they had capacity limits introduced, because of the recession. Again the results showed improved performance (e.g. less delayed and cancelled flights) through reductions in frequency. There was no significant change in markets serviced

The key observations from this analysis are as follows (table 1):

- Airfares change show a positive relationship to to changes in fuel prices

- Flights per day and Markets served show a positive relationship to changes in gross domestic product

- Flights per day and Markets served show a positive relationship to changes in airport capacity limits

- Delays and Cancellations change in proportion to Flights per day and Markets served

- Airline profitability shows a negative relationship to changes in airline airfares

- Airline profitability shows a negative relationship to changes in airport congestion

- Upgauging of airline fleets is unlikely to occur without the introduction of a new class of aircraft that has better efficiency for aircraft handling between 100-150 passengers.

- New York airports reacted differently to the new capacity limits, placed on these airports in 2008. LGA and EWR reduced schedules, because there was not opportunity to adjust their schedules to other timeslots. However
JFK depeaked their schedule and maintained their flights per day volume.

- Reduced delays in 2008 did not provide airlines relief in delay costs because of the increased fuel costs.

- Airports with capacity limits reduced operations and congestion, while increasing profitability.

- When the economy went into a severe recession, airports without capacity limits reduced operations and congestion, while increasing profitability.

\section{Future Analysis}

As the economy recovers, we expect that congestion will return unless capacity limits are imposed at SFO and PHL. Fuel prices have fluctuated significantly during the period of study. At the same time, the economy has suffered a recession. Further study may allow us to separate out the effect of economic conditions from the effects of fuel prices and allow us to see if ticket prices are more sensitive to the economic conditions or to fuel prices. Our future analysis will include performing statistical analysis of these relationships found to determine changes in airline airfares and passenger demand as a function of changes in fuel prices, gross domestic product and capacity limits. Additionally, the continual monitoring of ticket prices, schedule changes, aircraft assignment, and load factors over a variety of different economic impulses will help us to better predict future behaviors.

\section{Acknowledgements}

The authors acknowledge the technical database assistance provided by Guillermo Calderon-Meza of the Center for Air Transportation Systems and the support provided by Rosa Oseguera-Lohr and Mike Madson (NASA). This research was sponsored by NASA Award 06 AS2 060014.

\section{REFERENCES}

[1] http://www.faa.gov/about/initiatives/nextgen/be nefits/ 
[2] G. L. Donohue, R. D. Shaver III, “Terminal Chaos: Why U.S. Air Travel is Broken and How to Fix It", American Institute of Aeronautics \& Astronautics, Library of Flight, Editor: Ned Allen Spring, 2008.

[3] N. Xu, L. Sherry, and K. Laskey, "Multi-factor Model for Predicting Delays at U.S. Airports", Transportation Research Board, 88th Annual Meeting, January 11-15, 2008, Washington, D.C., 2008.

[4] L. Sherry, and G Donohue, "U.S. Airline Passenger Trip Delay Reports (2007\&2008)," Center for Air Transportation Systems Research Report, George Mason University, pp. 5, 2008.

[5] S. Lan, J.P. Clarke, and C. Barnhart, "Planning for robust airline operations: optimizing aircraft routings and flight departure times to minimize passenger disruptions," Transportation Science 40, pp. 15-28, 2006.

[6] B. Manley and L. Sherry, "Impact of ground delay program rationing rules on passenger and airline equity," Integrated Communications, Navigation and Surveillance Conference, 2008. ICNS 2008 , pp.1-11, 5-7 May 2008.

[7] C. E. Schumer, "Flight Delays Cost Passengers, Airlines and the U.S. Economy Billions". A Report by the Joint Committee Majority Staff, May 2008.

[8] J. Ferguson; K. Hoffman; L. Sherry; A. Kara, "Effects of Fuel Prices on Air Transportation Performance at New York and San Francisco Airports", 2009 ICNS Conference, 13-15 May 2009.

[9] P. Cox, New York Post, (May 26, 2008).

[10] The MITRE Corporation, "Capacity Needs in the National Airspace System (2007-2025)", FAA Fact 2 Report, pp.9, May 2007.

[11] The MITRE Corporation, "Capacity Needs in the National Airspace System (2007-2025)", FAA Fact 2 Report, pp.15, May 2007.

[12] Bureau of transportation statistics (BTS) databases and statistics. Accessed March 2010. http://www.transtats.bts.gov/

[13] Aviation system performance metrics (ASPM)complete, FAA.
[14] Performance Review Unit, Eurocontrol, "Evaluating the True Cost to Airlines of One Minute of Airborne or Ground Delay," University of Westminster Final Report, May, 2004.

[15] A. Kara, J. Ferguson, K. Hoffman, L. Sherry , "Estimating Domestic U.S. Airline Cost of Delay based on European Model" ,Accepted at 4th International Conference on Research in Air Transportation - ICRAT 2010, Budapest Hungary June 01 - 04, 2010

\section{Integrated Communications Navigation and Surveillance (ICNS) Conference}

May 11-13, 2010 